\title{
В преддверии юбилея: три века за 100 лет
}

\author{
Рассказывает ветеран Великой Отечественной войны, \\ первый директор НИИ «Платан", профессор В. П. Куклев
}

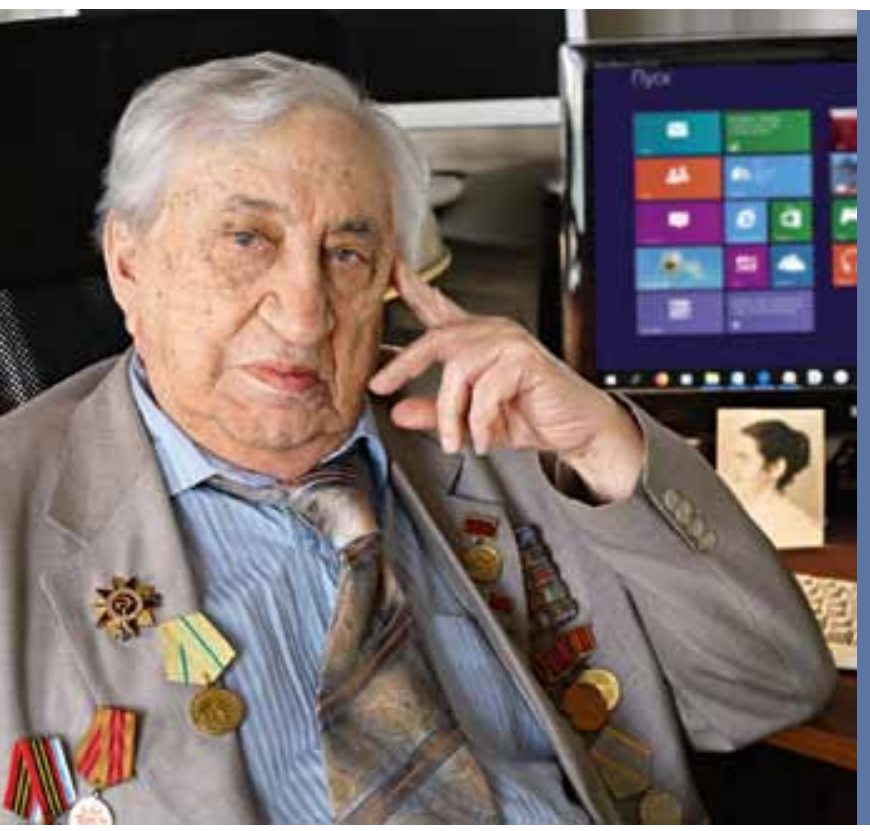

\author{
29 июля текущего года исполняется \\ 100 лет со дня рождения видного \\ российского специалиста в направлениях \\ разработки и применения компонентов \\ радиоэлектронной аппаратуры (РЭА), средств \\ отображения информации (СОИ) и систем \\ управления, ветерана Великой Отечественной \\ войны, профессора, д. т. н. Владимира \\ Петровича Куклева. \\ В преддверии этой знаменательной даты \\ Владимир Петрович рассказал нам о наиболее \\ значимых этапах своего жизненного \\ пути, а также поделился своим видением \\ дальнейшего развития ЭКБ и систем \\ управления двойного назначения.
}

Владимир Петрович, поздравлять с юбилеем заранее не принято, однако позвольте выразить восхищение тем, что вы отдали столько лет служению науке и технике и продолжаете активную деятельность в этой области. Что вас на это вдохновляет, или, как сейчас говорят, мотивирует к этому?

Вдохновляет жизнь, динамика развития науки и техники, постоянное желание познать новое, как можно больше оставить молодому поколению, внукам, правнукам.

Меня техника начала привлекать еще в детстве. Помню, когда мы с мамой переехали из моего родного села Мусо́рка Новобуянского района Куйбышевской (теперь Самарской) области в городок Абдулино соседней Чкаловской (ныне Оренбургской) области, мы расположились в небольшом доме с палисадником, примыкающим к железной дороге Куйбышев - Челябинск. Я любил рано вставать, взбираться на изгородь палисадника и наблюдать за проезжающими поездами. Более всего меня поражали паровозы, похожие на чудовища с огромными рычагами и колесами. А в паровозном депо был смонтирован поворотный круг, на который въезжали паровозы, и рабочие рычагами разворачивали их на 180, чтобы они могли ехать в другом направлении. я часами смотрел на эти операции.

Сейчас, оглядываясь назад, мне кажется, что я жил в трех веках. Эти паровозы, пароходы, кузнечное дело, которому, наряду с другими ремеслами, меня учили на уроках труда в средней школе имени М.И. Калинина города Бугуруслана, керосиновые лампы и свечи, на смену которым приходили "лампочки Ильича", - всё это еще дышало укладом 19 века.

Позже начался век 20-й с его стремительным развитием техники, индустриализацией, электрификацией страны, развитием средств связи, синтетических материалов, атомных, космических технологий, электроники и радиоэлектроники.

А сейчас на дворе 21 век - век интенсивного развития био-, нанотехнологий, информационно-коммуникационных, робототехнических систем, искусственного интеллекта.

смотреть в будущее и участвовать в этом прогрессе очень интересно.

В начале своего профессионального пути вы работали в области радиолокации. Как сложилось, что вы занялись именно этим направлением?

Когда по окончании школы я поступал в Саратовский государственный университет, меня очень привлекала физика. В СГУ я впервые познакомился с работами профессора П.В.Голубкова - новатора в ряде научных направлений вакуумной и твердотельной радиоэлектроники миллиметрового диапазона. Позже, в январе 1941 года, я перевелся в лгу, переехав 
в Ленинград, а во время летней сессии третьего курса началась Великая Отечественная война.

Мы, студенты ЛГУ, отправились на оборонные работы. Нам было поручено готовить полевые аэродромы в различных районах Ленинградской области. 7 сентября мы практически последним поездом вернулись в город с этих работ, а на следующий день вокруг него замкнулось кольцо - началась блокада Ленинграда. Мы всей студенческой группой подали заявления на добровольное вступление в Красную армию, нас зачислили в автотракторное училище, а после окончания курсов направили в батальоны аэродромного обслуживания. В феврале 1942 года по причине дистрофического истощения я был переправлен по "Дороге жизни" за пределы блокадного кольца. Участвовал в боях под Синявино в составе подразделений Волховского фронта по прорыву блокады с внешней стороны кольца навстречу войскам Ленинградского фронта. Был ранен и контужен, а после выздоровления был признан комиссией годным к нестроевой службе и отправился в 16 отдельную роту земного обеспечения самолетовождения, в которой прослужил до сентября 1945 года.

В этот период службы, за который я был награжден медалью "За боевые заслуги», мне довелось работать на приводной радиостанции типа ЗА. По штату на нее полагалось пять человек, но наш экипаж состоял всего из троих. По предложению командира роты я совмещал функции радиомеханика и электрика. Это стало возможным благодаря нашему рацпредложению автоматизировать передачу кода навигации: вместо того, чтобы передавать его часами вручную, мы приспособили механический привод телеграфной ленты.

После окончания войны я вернулся в ЛГУ и, закончив третий курс, перевелся в ЛЭтИ им. Ульянова (Ленина), решив, что получил фундаментальное университетское образование, а специальное техническое имеет смысл получить в техническом институте.

В марте 1949 года, когда я учился на пятом курсе и работал над дипломным проектом, я решил поступить на завод № 206 МСП старшим техником. Этот завод гидроакустического профиля получил годовой план по новой технике - морской радионавигационной системе, аналогичной системе Decca. Эта новая продукция составляла более половины годового объема выпуска завода.

С самого начала я столкнулся с извечной проблемой зависимости надежного функционирования РЭА от электронных компонентов. Я оказался на предприятии единственным специалистом по специальности «Радиотехника». Руководство завода придумало для меня нештатную должность - ведущий инженер заказа.
Ознакомившись с технологическими службами завода, я понял, что они имеют опытные кадры, но узким местом был участок радиотехнических и электронных измерений. Тогда я организовал небольшую группу для измерений критических параметров выходных блоков, определяющих навигационную точность. В этой работе большую роль сыграл новый осциллограф, срочно изготовленный по моему дипломному проекту и позволявший измерять параметры импульсов до 0,5 мкс.

\section{Еще в начале моей деятельности я столкнулся с проблемой зависимости надежности РЭА от электронных компонентов}

В самом конце декабря 1949 года сложилась критическая ситуация: из 16 заказанных заводу комплексов военной приемкой были приняты только 10. Выручили новые осциллографы и человеческая смекалка. Вместе с коллегой мы определили тонкие места блоков, требующие подбора электронных компонентов по параметрам, и за оставшиеся несколько дней до конца года были настроены, предъявлены и сданы ВП оставшиеся шесть комплексов. Годовой план был спасен!

Решение о приемке и выполнении заводом годового плана принимали лично приехавшие на завод начальник Главного управления Министерства судостроительной промышленности СССР Валерий Дмитриевич Калмыков, который впоследствии стал фактически моим учителем в области систем управления, и начальник ВП ВМФ, адмирал Василий Александрович Архипов.

В 1950 году Валерий Дмитриевич привлек меня к работе в КБ-1, будущем "Алмазе», в должности заместителя начальника лаборатории по исследованию точности измерений дальности фазовым методом радиолокационными станциями, а в 1953-1954 годах я в качестве старшего инженера Третьего главного управления (ТГУ) при Совете Министров СССР принимал участие в проведении полигонных испытаний систем ПВО, ответственным руководителем которых был Калмыков.

В 1954 году, после успешно завершенных испытаний, я в качестве уполномоченного ТГУ обеспечил контроль строительства и постановку на вооружение закрепленных объектов ПВО Москвы, а Валерий Дмитриевич был назначен министром радиотехнической промышленности СССР и предложил мне должность начальника отдела радионавигации и радиолокации.

В 1954 году вы участвовали в создании Центрального бюро применения электровакуумных приборов 
(ЦБП эВП). В чем заключались задачи этой организации?

Бюро создавалось по инициативе Александра Ивановича Шокина, тогда еще заместителя министра радиотехнической промышленности. Александр Иванович хорошо понимал, что в условиях активного развития радиоэлектроники крайне важной задачей для обеспечения надежности продукции было упорядочение применения ЭВП разнообразных типов, работающих в разных режимах.

Как я уже упомянул, мне пришлось столкнуться с проблемой недостаточной надежности РЭА по вине вакуумных приборов еще в начале моей деятельности на заводе № 206 МСП. По вопросу: "Кто виноват?» - бесконечно спорили разработчики и производители аппаратуры с разработчиками ЭВП. На самом деле это была обоюдная проблема. Большая часть причин преждевременных выходов ЭВП из строя заключалась в неправильных режимах их использования в аппаратуре. Разработчики аппаратуры должны были проектировать схемы с учетом изначального разброса и естественных изменений параметров ЭВП в процессе их работы. В то же время теории расчета радиотехнических схем с учетом разброса параметров компонентов, подобной теории допусков и посадок в машиностроении, в радиоэлектронике не было. Кроме того, в новой аппаратуре появлялись принципиально новые схемы, требовавшие новых параметров ЭВП, не предусмотренных в действовавших ТУ. Например, для блокинг-генераторов требовались импульсные параметры ламп порядка единиц ампер, в то время как статические параметры не превышали нескольких тысячных долей ампера. При этом распространенные лампы, в частности 6Н8С или 6Н1П, такими импульсными параметрами обладали, но выборочно, и в ТУ это прописано не было. Это приводило к необходимости подбора ламп.

Таким образом, в радиотехнике назрела крайняя необходимость ввода системы контроля за правильностью применения компонентов. Эта задача и была возложена на новое бюро. В соответствии с Распоряжением Совета Министров СССР о создании ЦБПЭВП, на разработчиков РЭА возлагалась обязанность правильности применения ЭВП соответственно режимам, предусмотренным ТУ на ЭВП, и обязательное согласование с ЦБП ЭВП. В виде исключения допускалось применение ЭВП в режимах, не предусмотренных ТУ но допустимых с точки зрения надежности работы при эксплуатации. В этих случаях предприятия должны были получить положительное заключение ЦБП ЭВП, без которого государственные комиссии не принимали в эксплуатацию новую РЭА. Рекомендовалось проводить обследование режимов использования ЭвП, показавших низкую надежность работы при эксплуатации аппаратуры.

А. И. Шокин предложил мне изучить соответствующее распоряжение, продумать как сформировать положение о ЦБП ЭВП и рассмотреть возможность организации бюро на базе отдела 210 НИИ-160. Я выехал в этот легендарный институт в город Фрязино, о котором был много наслышан. После знакомства с руководством и коллективом НИИ мной были подготовлены предложения по организации ЦБПЭВП, которые Александр Иванович поддержал. На следующий день вышел приказ по министерству об организации межведомственного ЦБП ЭВП при НИИ-160 на базе отдела 210, и мы приступили к работе.

Стоит отметить один важный момент: ЦБП ЭВП было решено сформировать не как бюрократическую контору, а как научно-исследовательский центр, объединяющий специалистов по грамотному применению ЭВП в РЭА. Проводимые в лабораториях бюро исследования и испытания различных режимов работы ЭВП, а также опытная эксплуатация ЭвП в реальных условиях на действующих объектах, организуемая и проводимая ЦБПЭВП, приносили положительные результаты в отношении повышения надежности и долговечности ЭВП, что было убедительным доказательством целесообразности создания бюро с организованной научной и испытательной базой.

Посвятив столько лет радиолокации и ЭКБ, вы перешли в область СОИ. Почему это произошло?

В 1963 году обострилась проблема обеспечения специальными электронно-лучевыми приборами (ЭЛП) диспетчерских пунктов управления авиацией, морским флотом и другими мобильными объектами. Помимо этого, правительством страны была поставлена задача запуска в 1967 году - к 50-летию Октябрьской революции - цветного телевещания. В 1963 году А. И. Шокин назначил меня начальником 8 управления, специализировавшегося в области электронных приборов отображения, а в 1965 году, после преобразования ГКЭТ в МЭП СССР, он поддержал мое предложение организовать головной институт по специальным ЭЛП и цветным кинескопам. Такой институт был создан, и я был назначен его директором. При институте был организован опытный завод. Кроме того, к нему были прикреплены пять базовых заводов.

С поставленными задачами НИИКЭЛ, в последствии преобразованный в НИИ «Платан», успешно справился, полностью устранил сложившийся дефицит специальных ЭЛП. Институтом и заводами было разработано и успешно выпускалось несколько серий электронных преобразователей всех возможных видов: сигнал-изображение, изображение-сигнал, 
сигнал-сигнал, изображение-изображение. Были разработаны и освоены в опытном производстве и на базовых серийных заводах важные для развития отечественной радиоэлектроники специальные ЭлП таких видов, как знакопечатающие, запоминающие высокояркостные, запоминающие осциллографические, преобразовательные запоминающие, функциональные счетно-решающие и др. Разрабатывались и реализовывались текущие и перспективные планы опережающего развития СОИ, в частности плоских жК-индикаторов для аппаратуры, работающей в полевых условиях; приборов для больших экранов коллективного пользования; высокояркостных приборов для проекции изображений на лобовом стекле мобильных и летательных аппаратов (ЛА).

После 17 лет руководства "Платаном" вы перевелись на должность начальника лаборатории. С чем это было связано?

Это произошло в 1982 году. Я сделал этот шаг, чтобы написать докторскую диссертацию и построить дачу, - во избежание лишних разговоров. Диссертацию написал и защитил ее в 1984 году в МИЭМ. Дачу построил в том же году.

Выбор института для продолжения научной деятельности был для меня предрешен. Сейчас НИИ автоматической аппаратуры носит имя академика Владимира Сергеевича Семенихина. С ним мне посчастливилось познакомиться на совещании в МРТП. Заняв должность директора НИИАА, он несколько раз приезжал к нам в «Платан». Владимир Сергеевич придавал большое значение электронным элементам для аппаратуры. Его особо интересовала возможность создания больших экранов, до 10 м², с высокой разрешающей способностью и яркостью.

После защиты докторской диссертации я предложил ему свои услуги, и он оперативно дал положительный ответ. Одной из первых задач, над которыми я начал работать в НИИАА, было определение перспективности использования принципов цифрового телевидения в специальной технике, автоматизированных системах управления. Наше предложение перейти на эту технологию было принято не сразу, оно не было поддержано Мнити - фактическим законодателем технического развития телевидения в нашей стране. Однако В.С. Семенихин на совещании главкомов с участием начальника Генерального штаба С.Ф.Ахромеева был очень убедителен, и всё пошло по новому, прогрессивному курсу. В НИИАА по моему предложению и при поддержке Владимира Сергеевича была поставлена НИР по созданию многофункционального аппаратно-программного комплекса сбора, обработки и отображения оперативной обстановки на фоне электронных карт местности (векторных и растровых) для АСУ ВС РФ («Центр»). Разработанный комплект экспериментальных образцов продемонстрировал свою эффективность на штабных учениях Дальневосточного военного округа в 1989 году.

\section{Мы стоим на пороге нового времени, с моей точки зрения - прежде всего времени нанорадиоэлектроники и искусственного интеллекта}

В 2016 году во время празднования 60-летия НИИАА имени академика В.С. Семенихина было отмечено много достижений по созданию прогрессивных автоматизированных систем управления под руководством этого выдающегося ученого и Человека с большой буквы. я думаю, что все, кому посчастливилось общаться и работать сним, еще много раз с глубокой благодарностью к нему переберут в памяти все эпизоды и события того периода.

Какие задачи, которые стоят в настоящее время перед предприятиями электронной и радиоэлектронной промышленности, по вашему мнению, наиболее актуальны?

Мы стоим на пороге нового времени, с моей точки зрения - прежде всего времени нанорадиоэлектроники и искусственного интеллекта. Нанорадиоэлектроника - это критическая прорывная технология и основа стратегического развития ИТ, систем связи и управления. Создание перспективных вычислительных и радиотехнических средств, соответствующих предъявляемым к ним повышенным техническим требованиям, а также требованиям импортонезависимости, невозможно без разработки и организации производства отечественной ЭКБ нового поколения на базе последних достижений науки и техники. Вся история развития электроники и радиотехники показывает: только появление новых электронных компонентов обеспечивает качественный скачок развития.

В 2005-2015 годах НИИАА в условиях жесткого конкурса получил четыре НИР и четыре ОКР по созданию ЭКБ для систем управления. Мне, как научному руководителю и главному конструктору этих работ, удалось обобщить результаты системного анализа инновационных исследований и разработок института, что позволило сформулировать пути создания ЭКБ нового поколения и разработки размернопараметрического ряда электронных модулей АРМ систем управления различных уровней и различного 
применения, включая космическое, авиационное, морское и наземное.

Ряд аспектов сформулированных подходов были мной изложены, в частности, на отчетном собрании российского отделения Международного дисплейного общества (SID) в марте 2014 года.

На основе проведенного анализа были сформули рованы семь принципов создания отечественной ЭКБ и аппаратуры систем управления нового поколения: импортонезависимость, использование в основе раз работки научных достижений, минимальная номенклатура, комплексная микроминиатюризация, типовая структура АРМ операторов и должностных лиц, унификация фундаментальных составляющих электронных модулей АРМ, создание специального прикладного ПО в соответствии с ТТЗ заказчика по функциональному назначению.

\section{Нужен системный подход, направленный на определение необходимых типов ЭКБ не дия отдельного радиотехнического
средства, а дия комплекса РЭА}

По крайней мере три из перечисленных принципов касаются унификации - как на уровне ЭКБ и модулей, так и на уровне компонентов систем...

Да, унификация - один из ключевых моментов. Сейчас в рамках импортозамещения проводятся достаточно высокозатратные ОКР, направленные на замену более 500 видов иностранной радиоэлектронной продукции. Это приведет к созданию различными компаниями, исходя из конкурентных соображений, неунифицированных и неперспективных компонентов. Для достижения большей эффективности как в использовании денежных средств и ресурсов, так и в получении высоких технических показателей нужен системный подход, направленный на определение необходимых типов ЭКБ не для отдельного радиотехнического средства, а для комплекса РЭА, объединенной однородными функциональными требованиями. При этом открывается возможность формирования типового ряда ЭКБ оптимальной номенклатуры, достаточной для построения систем различных уровней и назначений.

Определение современных требований к ЭКБ на основе системного подхода может быть реализовано в два шага. Первый шаг - сверху вниз, или от систем КЭКБ - позволит определить требования для конкретного образца техники, но не решит задачу оптимальной номенклатуры ЭКБ. Следующий шаг-снизу вверх, или от ЭКБ к системам - сделает возможным создание оптимальной унифицированной отечественной ЭКБ для широкого комплекса изделий, в том числе ВВСТ, в отличие от сложившегося подхода с привязкой разработки ЭКБ к конкретному образцу.

Среди перечисленных принципов прозвучало понятие "комплексная микроминиатюризация". Что в данном случае понимается под словом “комплексная"?

ЭКБ нового поколения принципиально отличается от традиционной прежде всего уровнем интеграции и микроминиатюризации. Перспективные электронные средства будут строиться на основе не дискретных компонентов и ИС, решающих отдельные задачи, а функционально законченных систем, реализованных в виде СБИС и микромодулей, таких как СнК и СвК, в том числе с использованием ПлиС.

Также отмечу, что комплексная микроминиатюризация позволит обеспечить необходимую защищенность ЭКБ и аппаратуры нового поколения от воздействия внешних факторов, характерных для таких областей применения, как космическая, авиационная, морская аппаратура и т.п.

Если говорить о системах управления, микроминиатюризация в первую очередь критична для таких важнейших их составляющих, как микровычислители и микрокоммуникаторы, а также СОИ индивидуального пользования нового поколения, предназначенные для дополненной реальности.

Принято считать, что в области полупроводниковых микросхем возможности развития во многом определяются объемами производства, поэтому для создания передовых ИС даже специального назначения необходим широкий гражданский рынок. Применимы ли эти рассуждения к СОИ? Как вы оцениваете возможности гражданского рынка для российских производителей?

Сразу отмечу, что, на мой взгляд, для развития техники первичен не рынок, первична научная деятельность. За многие годы работы на промышленных предприятиях я убедился в высокой эффективности глубоких поисковых исследований, выполняемых как в учреждениях академической науки, так и в отраслевых НИи и заканчивающихся предложениями о постановке прикладных работ, которые выполнялись на уровне конструкторских работ, но без трудоемкого оформления документации. Эта схема - от инноваций к приборам испытана десятилетиями.

А рынок... Это уже вопрос сбыта, коммерциализации. Рыночный принцип ведения народного хозяйства не оправдал себя как основной стимул повышения производительности труда и привел к падению 
уровня экономики. Плоды горбачёвской перестройки, положившей начало подходу, при котором рынок ставится на первое место, мы пожинаем до сих пор.

Отвечая на ваш вопрос, скажу, что секторы гражданского рынка электроники и радиоэлектроники потребительского назначения в России для отечественной промышленности очень ограничены. Здесь господствуют зарубежные фирмы. Поэтому производителям имеет смысл ориентироваться на продукцию специализированного, профессионального назначения, в частности медицинского, авиационного, транспортного.

Мною разработан ряд, на мой взгляд, перспективных предложений по созданию и выпуску некоторых видов продукции двойного назначения, в частности унифицированного защищенного микровычислительного комплекса универсального применения для различных систем управления, а также бортового комплекса захода и посадки ЛА.

О данном комплексе хотелось бы рассказать отдельно. Развитие авиации и новые тактические задачи требуют обеспечения посадки на необорудованные площадки в трудных условиях видимости, вплоть до соответствующих категориям ИКАО IIIA, IIIB и IIIC, в То время как существующие курсо-глиссадные системы основаны на наземных радиомаяках и предназначены для оборудованных ВПП. Мое предложение базируется на ряде собственных патентов. Предлагаемый комплекс включает стереоскопическую систему визуализации на базе сдвоенных видеодатчиков ИК-диапазона 8-14 мкм; стереоскопическую систему отображения закабинного изображения окружающей местности при заходе на посадку; многофункциональный 3D-дисплей на приборной доске; систему ГЛОНАСС/GPS с внешними активными антеннами; бортовой вычислительный блокс базой данных; бортовой высотомер вблизи земной поверхности высокой точности, основанный на принципе частотной модуляции; специальное ПО.

Вы упомянули такую организацию, как SID. Вы яВляетесь Старейшиной этого общества. Какую роль играет данная организация в отрасли СОИ в России?

Объединения, подобные SID, нужны хотя бы для того, чтобы быть в курсе тенденций развития дисплейной техники в мире. Читая статьи ученых различных стран в периодических журналах SID, мы знакомимся со свежими данными о мировых достижениях в данной области, а участвуя в семинарах российского и белорусского отделений этого общества, мы обмениваемся результатами своих исследований, что трудно переоценить.

Помимо научной и производственной, вы ведете преподавательскую деятельность. Как вы оцениваете уровень современных студентов и их интерес к профессии? Что, на ваш взгляд, могло бы помочь улучшить передачу знаний из поколения в поколение?

К сожалению, уровень современных студентов и их интерес к профессии, с моей точки зрения, низок, но не по их вине. Надуманная система оценки абитуриентов - ЕГэ - ведет к снижению уровня знаний. Интерес к профессии ограничен из-за недостатка научно-исследовательских организаций и промышленных предприятий; учащимся 9-11 классов на вопрос: «На кого учиться дальше и где потом работать?»-сложно дать себе ответ, лежащий в области промышленности.

Мне представляется более целесообразным вопрос передачи молодежи не знаний, а опыта старшего поколения, используя методы, которые становятся возможными в новых условиях. Развитие ИТ открывает широкие возможности для дистанционного образования, однако нужно очень тщательно продумать, как совместить этот метод с очным обучением, живым общением с преподавателями и профессорами.

Стоит упомянуть, что и сейчас очень эффективной схемой остается организация филиалов вузов на предприятиях и базовых кафедр. Благодаря этому студент в процессе обучения не только получает диплом инженера, а становится специалистом, готовым к практической деятельности.

В заключение нашего разговора хотелось бы вернуться к одной из важнейших вех вашего жизненного пути. В этом году исполняется 75 лет Победе в Великой Отечественной войне. Каким был для вас день 9 мая 1945 года?

Меня вместе с моими однополчанами тот день застал во фронтовых условиях под Кёнигсбергом. Каждый год этот праздник отмечается грандиозным салютом, но тот первый салют - залпы из всех видов орудий, сигнальные ракеты и следы трассирующих пуль в небе не забудется никогда.

Все эти годы, празднуя очередную годовщину Победы, мы вспоминали и другие победы нашего народа уже в мирной жизни. Это и восстановление разрушенных городов, и создание отечественного ядерного щита, и первенство в космосе, и все те достижения нашей промышленности, к которым и мы приложили свою руку.

\section{Спасибо за интересный рассказ.}

С В.П. Кукиевым беседовап Ю. С. Ковалевский.

Mатериал подготовлен при поддержке Международного дисплейного общества (SID) и личном содействии директора российского отделения SID B. В. Беляева. Фото: О.Ф. Сиensн 